\title{
Adaptive Nonlinear Model Predictive Control of the Combustion Efficiency under the NOx Emissions and Load Constraints
}

\author{
Zhenhao Tang*(D), Xiaoyan Wu and Shengxian Cao \\ School of Automation Engineering, Northeast Electric Power University, Jilin 132012, China; \\ wuxiaoyanneepu@hotmail.com (X.W.); caoshengxian@neepu.edu.cn (S.C.) \\ * Correspondence: tangzhenhao@neepu.edu.cn
}

Received: 19 March 2019; Accepted: 1 May 2019; Published: 8 May 2019

check for updates

\begin{abstract}
A data-driven modeling method with feature selection capability is proposed for the combustion process of a station boiler under multi-working conditions to derive a nonlinear optimization model for the boiler combustion efficiency under various working conditions. In this approach, the principal component analysis method is employed to reconstruct new variables as the input of the predictive model, reduce the over-fitting of data and improve modeling accuracy. Then, a k-nearest neighbors algorithm is used to classify the samples to distinguish the data by the different operating conditions. Based on the classified data, a least square support vector machine optimized by the differential evolution algorithm is established. Based on the boiler key parameter model, the proposed model attempts to maximize the combustion efficiency under the boiler load constraints, the nitrogen oxide (NOx) emissions constraints and the boundary constraints. The experimental results based on the actual production data, as well as the comparative analysis demonstrate: (1) The predictive model can accurately predict the boiler key parameters and meet the demands of boiler combustion process control and optimization; (2) The model predictive control algorithm can effectively control the boiler combustion efficiency, the average errors of simulation are less than $5 \%$. The proposed model predictive control method can improve the quality of production, reduce energy consumption, and lay the foundation for enterprises to achieve high efficiency and low emission.
\end{abstract}

Keywords: Combustion efficiency; NOx emissions constraints; boiler load constraints; least square support vector machine; differential evolution algorithm; model predictive control

\section{Introduction}

Large inertia and time delay of the coal-fired boiler burning process leads to a complicated model for a power station boiler. This makes its direct control difficult [1]. The combustion situation could be directly described with the boiler combustion efficiency. Thus, it could be considered as an important feature for boiler control and optimization. On the other hand, nitrogen oxides (NOx) generated from combustion emissions are known as significant environmental pollutants [2]. Thus, combustion optimization should be considered due to the economy and safety necessities. A high precision predictive model is required for combustion optimization.

Mechanism models, statistic models, and data-driven models are the three main models that have been proposed in the literature for the estimation of boiler combustion efficiency. A variety of mechanism models have been derived for the boiler combustion efficiency using the physical principles. For example, the superiority of a gray-box system identification method to the computational fluid dynamics (CFD) method for NOx emission modeling in a coal-fired power plant has been demonstrated [3]. An energy balancing-based model has been employed in Reference [4] to propose 
an effective method for the boiler combustion efficiency estimation. According to the experimental results presented in these papers, a good approximation could be achieved through the proposed models under certain constraints, however, their performance could be influenced by real operation parameters. This limits their application in practical production. Accordingly, employing these models in modern control methods is difficult. Several statistics-based models have been proposed for boiler combustion efficiency prediction in the literature [5-7]. In Reference [5], an autoregressive integrated moving average (ARIMA) model has been proposed, based on simulation data to predict the boiler combustion efficiency. The thermodynamic principles have been employed to develop a dynamic model for an ultra-supercritical coal-fired once-through boiler-turbine unit [6]. In Reference [7], the prediction accuracy of the boiler combustion efficiency has been verified through a partial least squares (PLS) model. Despite their simplicity and usefulness, these models are too sensitive to measurement errors. This makes them unsuitable for designing a model-based controller. Various data-driven models have been utilized in optimization-based controllers. Artificial neural networking (ANN) [8], back-propagation (BP) [9], and multilayer perceptron (MLP) neural networks [10] have been employed to predict the boiler combustion efficiency. Although the prediction accuracy of these models is satisfactory, over-fitting phenomena could have occurred in them. Moreover, a least square support vector machine (LSSVM) model has been extracted from the real data to obtain the optimal combustion parameters [11,12]. Here, the LSSVM was employed to construct the boiler load, the NOx emissions, and the boiler combustion efficiency models of the coal-fired boiler. Moreover, the differential evolution (DE) algorithm has been utilized for online optimization of the LSSVM parameters for different problems.

The experimental simulation data has been collected from the supervisor information system (SIS) or distribution control system (DCS). To improve the prediction accuracy and reduce the computation time, principal component analysis (PCA) has been selected to process the experimental data $[13,14]$. In addition, different operating conditions could be distinguished via the k-nearest neighbor (KNN) classifier. Accordingly, the modeling prediction accuracy could be improved.

Various predictive model-based optimization methods have been utilized to control the boiler combustion efficiency. In Reference [15], a new hybrid jump particle swarm optimization (PSO) algorithm has been proposed to tune the proportional integral (PI) controller that has been designed for the boiler-turbine unit control. Moreover, a genetic algorithm (GA) has been utilized to obtain the optimal controller parameters of the low NOx emissions in the presence of the invariable load [16]. The active disturbance rejection controller (ADRC) was proposed by Han, and it had a large stability margin and bandwidth. However, the method required the control torque disturbance to be set [17]. A new hybrid model-free control and virtual reference feedback tuning (MFC-VRFT) method was $f$ proposed to solve the complex problem of traditional controllers. This method can solve the controller optimization problem well. However, multiple PI controller parameters must be considered [18]. To improve the boiler efficiency under the load constraint by finding the optimal parameters, the DE algorithm has been employed too [19-22]. Due to its highly robust performance, the model predictive control (MPC) has been employed in various control applications, such as civil engineering control [19,20], machinery manufacturing control [21] and steel industry control [22].

Improving the boiler combustion efficiency under NOx emissions and load constraints by using a nonlinear adaptive model predictive controller is the main goal of the current paper. A DE-based LSSVM algorithm and the feature selection approach are employed to extract appropriate models for the NOx emissions, the boiler load, and the boiler combustion efficiency for different operation conditions. This predictive model is employed to present an optimization model for improving boiler combustion efficiency under NOx emissions and boiler load constraints. Finally, a DE algorithm is utilized for solving the optimization model or equivalently finding the optimal control parameters.

This paper is organized as follows. The boiler combustion process is illustrated in Section 2. A nonlinear predictive model for the coal-fired boiler is extracted in Section 3 and its performance is validated through appropriate comparative models. An optimized output control scheme for 
the coal-fired boiler is presented in Section 4. The effectiveness of the proposed control structure is investigated through simulations. The concluding remarks are given in Section 5.

\section{Background}

A super-critical 600MW coal-fired boiler produced by the Harbin Boiler Plant Limited Liability Company is considered. The coal preparation system, the burner, the heating surface, and the air preheater are its main components. The boiler production process is shown in Figure 1. And the relation variables measurement points are marked in the figure. The coal in the coal hopper is fed into the coal mill via a belt conveyor, the pulverized coal and the primary air mixture via the milling system are fed into the combustion chamber. The steam generator combustion releases energy to produce saturated steam. Then, the superheated steam of a specific temperature is collected into main-pipe steam via the superheater, the superheated steam with a certain pressure enters the turbine's cylinder to drive the generator to generate electricity. Meanwhile, the flue gas is generated in the combustion process. In addition, to convert saturated steam into superheated steam, preheated air is preheated by boiler feed water and the air preheater via the economizer.

Flue gas is extracted from the boiler through the appropriate exhaust fans. The flue dust is separated from the electrostatic precipitate after exhausting flue gas into the atmosphere via an $80 \mathrm{~m}$ high stack. The bottom ash (slag) and the flue dust are disposed of via the hydraulic system and transported through the pipelines to the landfill. When the furnace flame temperature rises above $900{ }^{\circ} \mathrm{C}$ in the boiler combustion process, the coal undergoes thermal decomposition and is further oxidized into NOx, accompanied by the reduction reaction of NOx. The producing and reducing NOx are not only related to the characteristics of coal, the state of NOx in coal, the distribution ratio of nitrogen in volatile and coke during nitrogen thermal decomposition of coal and their respective components, but is also related to the oxygen concentration and combustion temperature. The NOx produced by the coal combustion in the boiler is discharged from the chimney into the surrounding environment. It could be harmful to the atmosphere and the environment. Moreover, the boiler load leads to unsafe boiler running and a low fuel utilization ratio. Therefore, the operation variables should be controlled to achieve the optimal boiler combustion efficiency under the NOx emissions and boiler load constraints. It leads to an interesting research area.

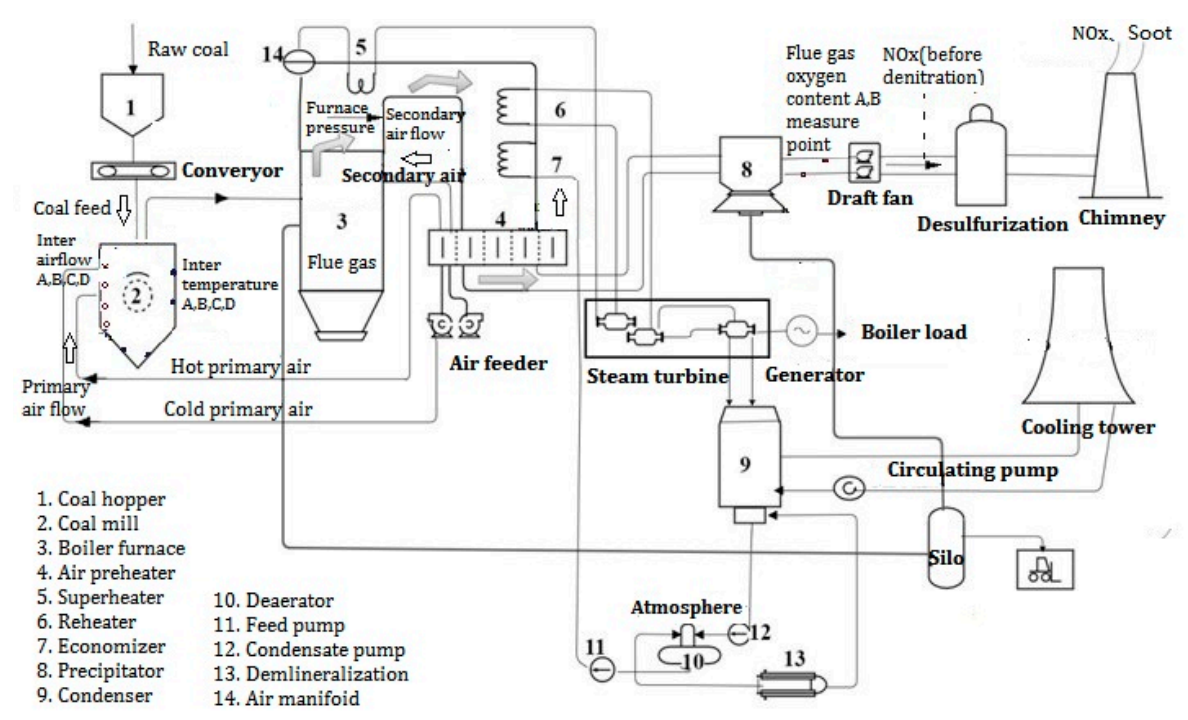

Figure 1. The description of coal-fired boiler production process.

\section{Nonlinear Dynamic Prediction Model}

The NOx emissions, the boiler load, and the boiler combustion efficiency could be described through nonlinear dynamic prediction models. These models are described in this section. The PCA 
algorithm is employed to reconstruct new variables as the predictive model inputs (see Section 3.1). This provides relevant information on the input parameters. The basic principles of the KNN classifier are introduced in Section 3.2. The prediction model is constructed in Section 3.3. The evaluation indices for model performance verification are defined in Section 3.4. Finally, the prediction performance of the proposed model is verified in Section 3.4.

\subsection{Data Selection}

The boiler efficiency, boiler load and NOx emission depend on various parameters, such as the coal feed, the main feed-water flow, the primary airflow, and the secondary airflow. The combustion mechanism and empirical analysis give eighteen boiler parameters that are gathered from the DCS. These parameters are defined in Table 1 . The parameter name in the table is important related variables of the boiler efficiency (B), boiler load (L) and NOx emissions $\left(\mathrm{N}_{\mathrm{x}}\right)$. Since the mentioned parameters have a different range, the data should be standardized. This improves the prediction accuracy. All the data are scaled according to the following equation:

$$
S_{n}^{k}=\frac{X_{n}^{k}-\frac{1}{K} \sum_{k=1}^{K} X_{k}^{n}}{\sqrt{\frac{1}{K-1} \sum_{k=1}^{K}\left(X_{k}^{n}-\frac{1}{K} \sum_{k=1}^{K} X_{k}^{n}\right)^{2}}}
$$

where $S_{k}^{n}$ represents the $n$ dimensional production parameters under data standardization, $X_{k}^{n}$ represents the meta-data with the dimension $n$ for the $k$ th sample, and $K$ is the number of the data set.

Table 1. The main boiler parameters.

\begin{tabular}{|c|c|c|c|c|c|}
\hline \multicolumn{2}{|c|}{ Name } & Nomenclature & Symbol & Unit & Classical \\
\hline \multirow{15}{*}{ Input variable } & \multirow{8}{*}{$\begin{array}{c}\text { Controllable } \\
\text { variable }\end{array}$} & Coal feed & Fc & $\mathrm{t} / \mathrm{h}$ & $\mathrm{B} / \mathrm{L} / \mathrm{N}_{\mathrm{x}}$ \\
\hline & & Main feed-water flow & $M$ & $\mathrm{t} / \mathrm{h}$ & $\mathrm{B} / \mathrm{L} / \mathrm{N}_{\mathrm{x}}$ \\
\hline & & Coal mill inlet airflow A & $A_{1}$ & $\mathrm{t} / \mathrm{h}$ & $\mathrm{B} / \mathrm{L} / \mathrm{N}_{\mathrm{x}}$ \\
\hline & & Coal mill inlet airflow B & $A_{2}$ & $\mathrm{t} / \mathrm{h}$ & $\mathrm{B} / \mathrm{L} / \mathrm{N}_{\mathrm{x}}$ \\
\hline & & Coal mill inlet airflow $\mathrm{C}$ & $A_{3}$ & $\mathrm{t} / \mathrm{h}$ & $\mathrm{B} / \mathrm{L} / \mathrm{N}_{\mathrm{x}}$ \\
\hline & & Coal mill inlet airflow D & $A_{4}$ & $\mathrm{t} / \mathrm{h}$ & $\mathrm{B} / \mathrm{L} / \mathrm{N}_{\mathrm{x}}$ \\
\hline & & Primary air flow & $P_{a}$ & $\mathrm{t} / \mathrm{h}$ & $\mathrm{B} / \mathrm{L} / \mathrm{N}_{\mathrm{x}}$ \\
\hline & & Secondary air flow & $S$ & $\mathrm{t} / \mathrm{h}$ & $\mathrm{B} / \mathrm{L} / \mathrm{N}_{\mathrm{x}}$ \\
\hline & \multirow{7}{*}{ State variable } & The flue gas oxygen content $\mathrm{A}$ & $\mathrm{O}_{1}$ & $\%$ & $\mathrm{~B} / \mathrm{N}_{\mathrm{x}}$ \\
\hline & & The flue gas oxygen content $B$ & $\mathrm{O}_{2}$ & $\%$ & $\mathrm{~B} / \mathrm{N}_{\mathrm{x}}$ \\
\hline & & Coal mill inlet temperature A & $T_{1}$ & ${ }^{\circ} \mathrm{C}$ & B \\
\hline & & Coal mill inlet temperature B & $T_{2}$ & ${ }^{\circ} \mathrm{C}$ & $\mathrm{B} / \mathrm{N}_{\mathrm{x}}$ \\
\hline & & Coal mill inlet temperature $C$ & $T_{3}$ & ${ }^{\circ} \mathrm{C}$ & B \\
\hline & & Coal mill inlet temperature D & $T_{4}$ & ${ }^{\circ} \mathrm{C}$ & $\mathrm{B} / \mathrm{N}_{\mathrm{x}}$ \\
\hline & & Furnace pressure & $P$ & $\mathrm{~Pa}$ & B \\
\hline \multirow{3}{*}{\multicolumn{2}{|c|}{ Output variable }} & NOx emissions in flue gas & $N_{x}$ & $\mathrm{mg} / \mathrm{m}^{3}$ & \\
\hline & & Boiler combustion efficiency & $B$ & $\%$ & \\
\hline & & Boiler load & $L$ & MW & \\
\hline
\end{tabular}

Due to the interaction between these parameters, the obtained prediction accuracy is low. Thus, the PCA method is employed for generating the required input for the prediction model and reducing the input dimension. The input variables are composed of controllable variables and state variables. Fc, $M, A_{1}, A_{2}, A_{3}, A_{4}, P_{a}, S$ are the most representative control variables in Table 1.

\subsection{Classification of Operating Conditions}

The actual production process runs under several operating conditions, and their parameters may change. Thus, a KNN algorithm is applied to separate different operating conditions. The K-value selection, distance measurement and the classification rule are three main stages in the KNN 
classification method. Firstly, the KNN algorithm selects the $\mathrm{K}$ value of the fixed sample data via cross-validation. Secondly, the distance measurement function is carried out for different operating conditions. The Euclidean distance describing with the following equation is selected for the distance measurement:

$$
d_{1,2}=\sqrt{\sum_{l=1}^{n}\left(S_{1 l}-S_{2 l}\right)^{2}}
$$

where $d_{1,2}$ is the Euclidean distance between two actual production parameters with the dimension $n$, and $S_{1 l}$ and $S_{2 l}$ are the $l$ th components of their corresponding standard deviations.

The test set is input and compared with a training set, the corresponding feature when the data and label in the training set are thus known. Corresponding features are determined by computing the Euclidean distance between the objects as a non-similarity index objects. Finally, the majority voting method is employed to classify the new sample data, and the corresponding model is utilized for the prediction. The greedy algorithm is employed to distinguish different operating conditions from the standard deviation distance of the clustering center. The sample data are divided into two groups. In this study, the boiler combustion efficiency, the boiler load, and the NOx emissions are considered as the operation conditions, respectively.

\subsection{Construction of the Predictive Model}

The LSSVM is adopted to construct the predictive model while the DE algorithm is utilized to find the optimal parameters of the LSSVM. The boiler load, NOx emissions and boiler combustion efficiency are divided into the $\mathrm{H}$ group data under the classified working conditions, then step 1 to 6 is executed, respectively. Each set of data represents a class of working conditions. The flowchart of the DE-based LSSVM (DELSSVM) algorithm is shown in Figure 2. The measurement models under corresponding working conditions are established by using the DE algorithm to the optimal LSSVM method. A description of the relationship between the input parameters and the boiler major parameters is given below:

Step 1: Divide data 1 (the NOx emissions samples set), data 2 (the boiler combustion efficiency samples set), and data 3 (the boiler load samples set) into training and test data, in accordance with the $\mathrm{H}$ groups operating conditions.

Step 2: Initialize the DE swarm randomly within the search space and adjust these parameters: $N p$ as the population size, $D$ as the population dimension, $g$ as the iteration number, $G$ as the maximum iterations, $F$ and $C R$ as the alternating and mutant probabilities, $C$ and $\sigma^{2}$ as the regularization and kernel parameters ( $N p=500, D=2, G=1000, F=0.7, C R=0.9$ are considered in this paper).

Step 3: Construct the LSSVM model using each individual correspondent with the kernel parameters value of the LSSVM and the model data of the $h$ th working conditions, the predictive model number of $N p$ are obtained by training, radial based function (RBF) kernel function is used in the LSSVM model:

$$
\begin{gathered}
f(x)=\sum_{k=1}^{K} a_{h} K\left(x_{k}, x\right)+b \quad k=1,2, \ldots, K \\
K\left(x_{k}, x\right)=\exp \left|\left(\frac{\left\|x_{k}-x\right\|^{2}}{2 \sigma^{2}}\right)\right|
\end{gathered}
$$

where $f(x)$ is the predictive value, $a_{h}$ and $b$ represent model parameters, $x_{k}$ is the $h$ th input parameter of the training sample, $K$ is the number of training sets, $K\left(x_{k}, x\right)$ are the LSSVM kernel parameters, $\sigma^{2}$ is the width of the RBF function, and the DE algorithm is used to obtain $\sigma^{2}$.

Step 4: Calculate the prediction root mean square error $(\varepsilon(k))$ for every particle $(f(k))$ as:

$$
\varepsilon(k)=\sqrt{\left(\sum_{k=1}^{N}\left|Y_{k}-f\left(x_{k}\right)\right|^{2}\right) / N}
$$


where $Y_{k}$ is the $k$ th true value and $f\left(x_{k}\right)$ is the $k$ th prediction value, and $N$ is the number of data sets.

Step 5: If $g=G$, stop the algorithm and go to Step 6. Otherwise, update the particles according to Equations (6)-(8) and return to Step 3.

$$
\begin{aligned}
& V_{j, g+1}=x_{j, g}+F\left(x_{b e s t . g}-x_{j, g}\right)+F\left(x_{r 1, g}-x_{r 2, g}\right) \\
& g=1, \ldots, G, j=1, \ldots, N \\
& U_{j, g+1}^{i}=\left\{\begin{array}{c}
V_{j, g^{\prime}}^{i} \operatorname{rand}_{i}(j) \leq C R, i=\operatorname{randn}_{j} \\
x_{j, g^{\prime}}^{i} \operatorname{rand}_{i}(j)>C R, i \neq \operatorname{randn}_{j}
\end{array}\right. \\
& i=1,2, \ldots, D, g=1, \ldots, G, j=1, \ldots, N \\
& x_{j, g+1}=\left\{\begin{array}{l}
U_{j, g}, f\left(U_{j, g}\right)<f\left(x_{j, g}\right) \\
x_{j, g}, f\left(U_{j, g}\right) \geq f\left(x_{j, g}\right)
\end{array}\right. \\
& g=1, \ldots, G, j=1, \ldots, N
\end{aligned}
$$

where $V_{j, g+1}$ is the $j$ th individual in the $(g+1)$ th iteration; $x_{b e s t, g}$ is the best individual in iteration $g ; j, r 1, r 2$ are different random integer numbers in the interval $[1, N p] ; F \in[0,2]$ is the alternating probability; $U_{j, g+1}^{i}$ is the $j$ th individual in the $(g+1)$ th iteration and the dimension parameter of the $i$ th individual; rand () means a random number witha uniform distribution in the interval $[0,1] ; C R \in[0,1]$ is the crossover probability and $f\left({ }^{*}\right)$ is the individual fitness function value.

Step 6: Calculate the optimal penalty factor $C$ and the kernel function $\sigma^{2}$ as well as the predictive model output.

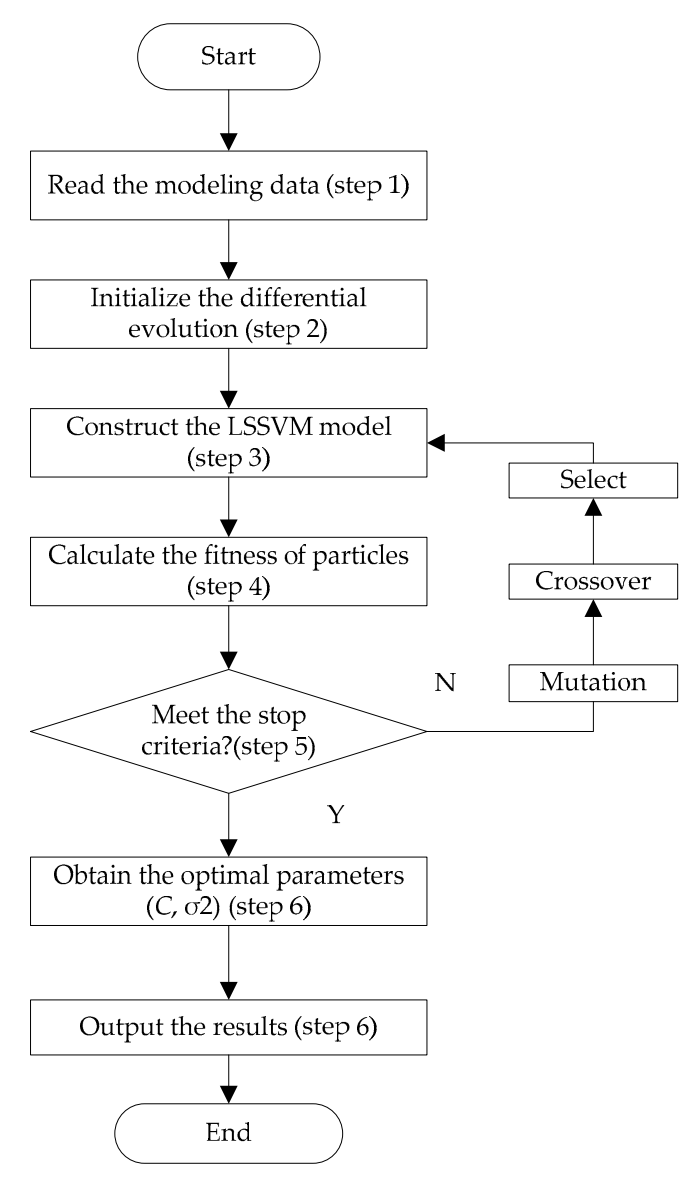

Figure 2. Flowchart of the differential evolution-based least square support vector machine (DELSSVM) algorithm. 
The model input variables are composed of state variables and controllable variables given in Table 1. And the prediction models for the boiler combustion efficiency, the NOx emissions and boiler load for different operating conditions are described as:

$$
\begin{gathered}
Y_{B, h}=f\left(F c, M, A_{1}, A_{2}, A_{3}, A_{4}, P_{a}, S, O_{1}, O_{2}, T_{1}, T_{2}, T_{3}, T_{4}, P, \sigma_{B}^{2}, w_{B}, C, e_{i, B}, a_{i, B}, b_{B}, B^{*}\right) \\
Y_{N_{x}, h}=f\left(F c, M, A_{1}, A_{2}, A_{3}, A_{4}, P_{a}, S, O_{1}, O_{2}, T_{1}, T_{2}, \sigma_{N_{x}}^{2}, w_{N_{x}}, C_{N_{x}}, e_{i, N_{x}}, a_{i, N_{x}}, b_{N_{x}}, N_{x}^{*}\right) \\
Y_{L, h}=f\left(F c, M, A_{1}, A_{2}, A_{3}, A_{4}, P_{a}, S, \sigma_{L^{\prime}}^{2}, w_{L}, C_{L}, e_{i, L}, a_{i . L}, b_{L}, L^{*}\right)
\end{gathered}
$$

where $Y_{B, h}, Y_{N x, h}$ and $Y_{L, h}$ are the predicted values for the boiler efficiency, the NOx emissions and the boiler load under the $h$ th operating condition, respectively; $F c, M, A_{1}, A_{2}, A_{3}, A_{4}, P_{a}, S, O_{1}, O_{2}, T_{1}, T_{2}$, $T_{3}, T_{4}, P$ are the corresponding symbols for operating parameters given in Table $1 ; \sigma_{B}{ }^{2}, \sigma_{N_{x}}^{2}$ and $\sigma_{L}^{2}$ are the kernel parameters of boiler efficiency, NOx emissions and boiler load, respectively; $\boldsymbol{w}_{B}, \boldsymbol{w}_{N x}$ and $w_{L}$ are the weight vectors of boiler efficiency, NOx emissions and boiler load, respectively; $e_{i, b}, e_{i, N x}$ and $e_{i, L}$ are the loss functions of the boiler efficiency, NOx emissions and boiler load, respectively; $a_{i, B}, a_{i, N x}$ and $a_{i, L}$ are the lagrange multipliers of boiler efficiency, NOx emissions and boiler load, respectively; $b_{B}, b_{N x}$ and $b_{L}$ are the constants of boiler efficiency, NOx emissions and boiler load, respectively; $N_{x}^{*}$, $B^{*}$ and $L^{*}$ are the previous values for the boiler combustion efficiency, the NOx emissions and the boiler load (at previous sample time), respectively.

\subsection{Model Validation and Analysis}

\subsubsection{Experiment Setup}

The experimental data collected from the distribution control system (DCS) in the power plant are defined in Table 2. The positive balance method is adopted to calculate the boiler efficiency according to the relevant factors (input variables) of boiler efficiency. The input variables of boiler efficiency are shown in Table 1. The input variables of the predictive model are obtained according to Equations (9-11) under two operating conditions. All of these simulations are performed through the MATLAB R2014a environment on a PC with Intel Core TM i5 $(2.50 \mathrm{GHz})$ processor, and 2.0 GB RAM, and Windows 10 32bit operating system.

Table 2. Dataset1.

\begin{tabular}{ccccccc}
\hline \multirow{2}{*}{ Parameter } & \multicolumn{3}{c}{ Number (Condition 1) } & \multicolumn{3}{c}{ Number (Condition 2) } \\
\cline { 2 - 7 } & $\boldsymbol{N}_{\boldsymbol{x}}$ & $\boldsymbol{B}$ & $\boldsymbol{L}$ & $\boldsymbol{N}_{\boldsymbol{x}}$ & $\boldsymbol{B}$ & $\boldsymbol{L}$ \\
\hline Train data (samples) & 800 & 800 & 800 & 600 & 600 & 600 \\
Test data (samples) & 300 & 300 & 300 & 270 & 270 & 270 \\
Sample Interval (min) & 1 & 1 & 1 & 1 & 1 & 1 \\
Input variable & 13 & 16 & 9 & 13 & 16 & 9 \\
Output variable & 1 & 1 & 1 & 1 & 1 & 1 \\
\hline
\end{tabular}

\subsubsection{The Model Performance Evaluation Indicators}

To compare the performance of the proposed model with other models, three evaluation indicators are defined in Table 3. These indicators could evaluate model prediction accuracy. These indicators include mean absolute error (MAE), mean absolute percentage error (MAPE), root mean square error (RMSE). These indicators can evaluate the average prediction ability of the model for each data point. 
Table 3. The indicators for the model performance evaluation.

\begin{tabular}{ccc}
\hline Metric & Definition & Equation \\
\hline MAE & Mean absolute error & $M A E=\left(\sum_{k=1}^{K}\left|Y_{k}-\hat{Y}_{k}\right|\right) / K$ \\
MAPE & Mean absolute percentage error & $M A P E=\left(\sum_{k=1}^{K}\left|Y_{k}-\hat{Y}_{k}\right| / Y_{k}\right) / K$ \\
RMSE & Root mean square error & $R M S E=\sqrt{\left(\sum_{k=1}^{K}\left|Y_{k}-\hat{Y}_{k}\right|^{2} /(K-1)\right)}$ \\
\hline
\end{tabular}

\subsubsection{Experimental Result Analysis}

In this section, the approach DDMMF is proposed as the predictive model in this paper, the prediction performance of the proposed model is compared with the ARIMA model in Reference [5], the PLS model in Reference [7], and the MLP model in Reference [10]. In the first case, the predicted results of the proposed model for operating condition 1 are compared with the corresponding ones obtained from the MLP, ARIMA and PLS models. The predicted values for the boiler combustion efficiency, the NOx emissions, and the boiler load for different prediction models are shown in Figure 3, while their corresponding prediction errors are compared in Figure 4. The evaluation indicators obtained for these predicted values are compared for various prediction models. These comparative results are given in Table 4. The predicted values for operating condition 2 are compared in Figure 5, while their corresponding prediction errors are given in Figure 6. Table 5 compares the prediction evaluation indicators for operating condition 2.

For operating condition 1, the best fit to the real values was achieved by the DDMMF algorithm (see Figures 3 and 4). Moreover, Table 4 demonstrates that the smallest evaluation values, or equivalently, the best prediction capability could be obtained by the proposed method. The same results for operating condition 2 could be derived from Figures 5 and 6 and Table 5. In summary, the following quantitative results could be obtained from these simulations.
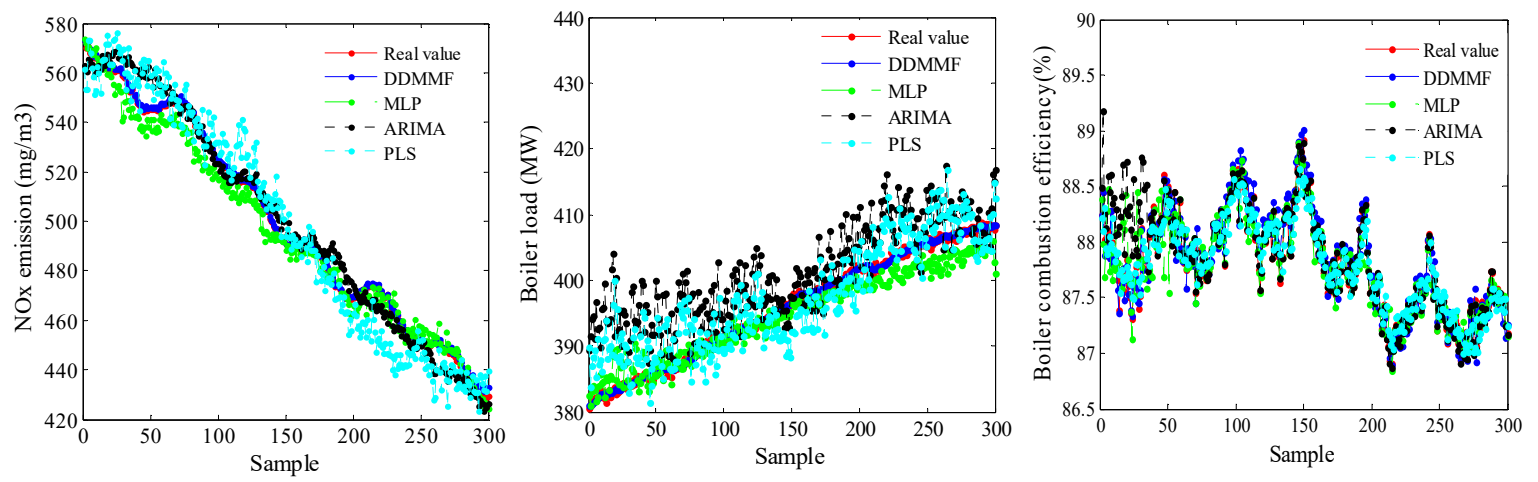

Figure 3. The predicted values obtained from different prediction models for operating condition 1.
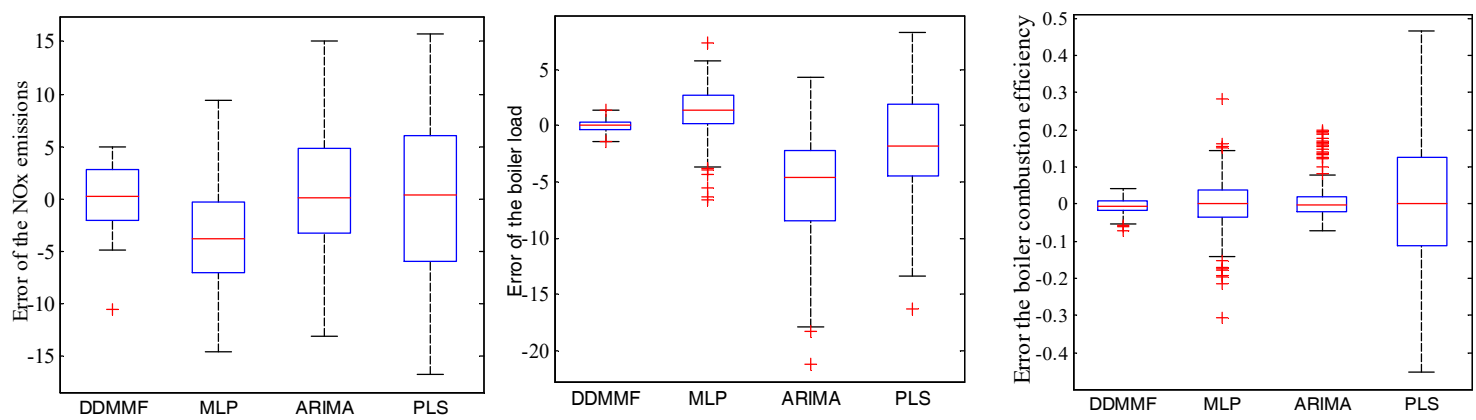

Figure 4. The prediction errors obtained from different prediction models for operating condition 1. 
Table 4. The prediction evaluation indicators of different objects for different models in operating condition 1.

\begin{tabular}{cccccccccc}
\hline & \multicolumn{3}{c}{ NOx Emissions } & \multicolumn{3}{c}{ Boiler Load } & \multicolumn{3}{c}{ Boiler Efficiency } \\
\hline Model & $\begin{array}{c}\text { MAE } \\
\left(\mathbf{m g} / \mathbf{m}^{3}\right)\end{array}$ & $\begin{array}{c}\text { RMSE } \\
\left(\mathbf{m g} / \mathbf{m}^{3}\right)\end{array}$ & MARE (\%) & $\begin{array}{c}\text { MAE } \\
\mathbf{( M W )}\end{array}$ & $\begin{array}{c}\text { RMSE } \\
\mathbf{( M W )}\end{array}$ & $\begin{array}{c}\text { MARE } \\
\mathbf{( \% )}\end{array}$ & $\begin{array}{c}\text { MAE } \\
\mathbf{( \% )}\end{array}$ & $\begin{array}{c}\text { RMSE } \\
\mathbf{( \% )}\end{array}$ & MARE (\%) \\
\hline DDMMF & 1.697 & 13.466 & $4.9 \times 10^{-4}$ & 0.001 & 4.244 & 0.001 & 0.010 & 0.162 & $7.3 \times 10^{-5}$ \\
MLP & 1.766 & 14.138 & $9.4 \times 10^{-4}$ & 0.029 & 11.567 & 0.011 & 0.058 & 0.184 & $2.0 \times 10^{-4}$ \\
ARIMA & 2.559 & 28.249 & $1.9 \times 10^{-3}$ & 3.520 & 21.563 & 0.789 & 0.040 & 0.712 & $5.1 \times 10^{-4}$ \\
PLS & 2.321 & 15.844 & $3.0 \times 10^{-3}$ & 0.963 & 35.940 & 0.631 & 0.118 & 1.628 & $2.8 \times 10^{-4}$ \\
\hline
\end{tabular}
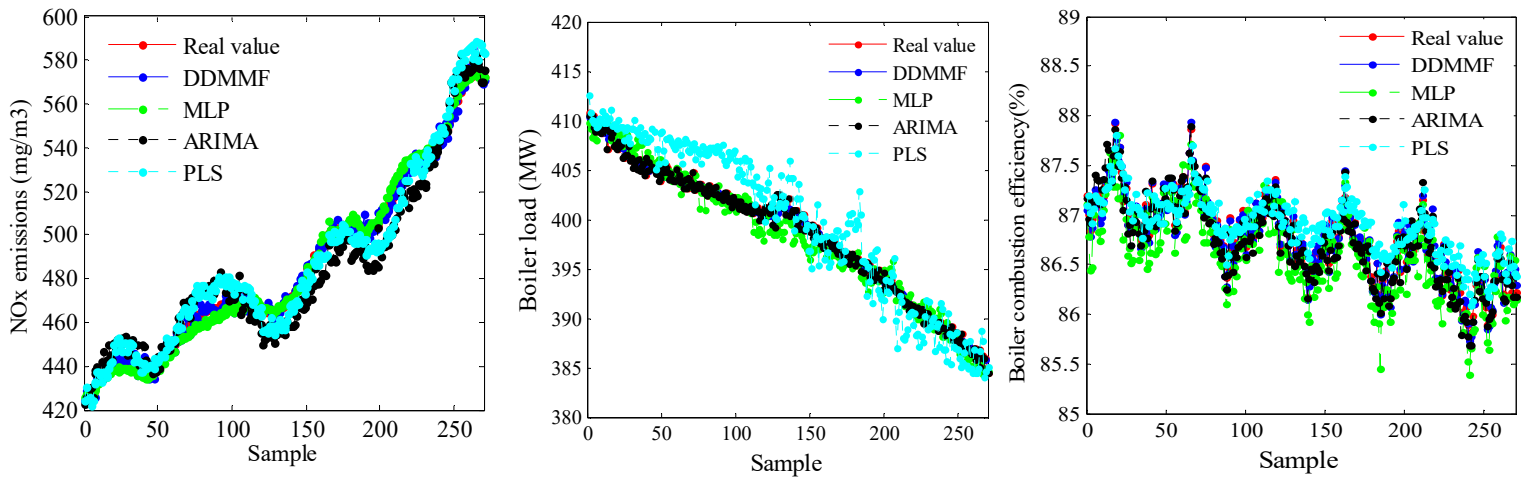

Figure 5. The predicted values obtained from different prediction models for operating condition 2.
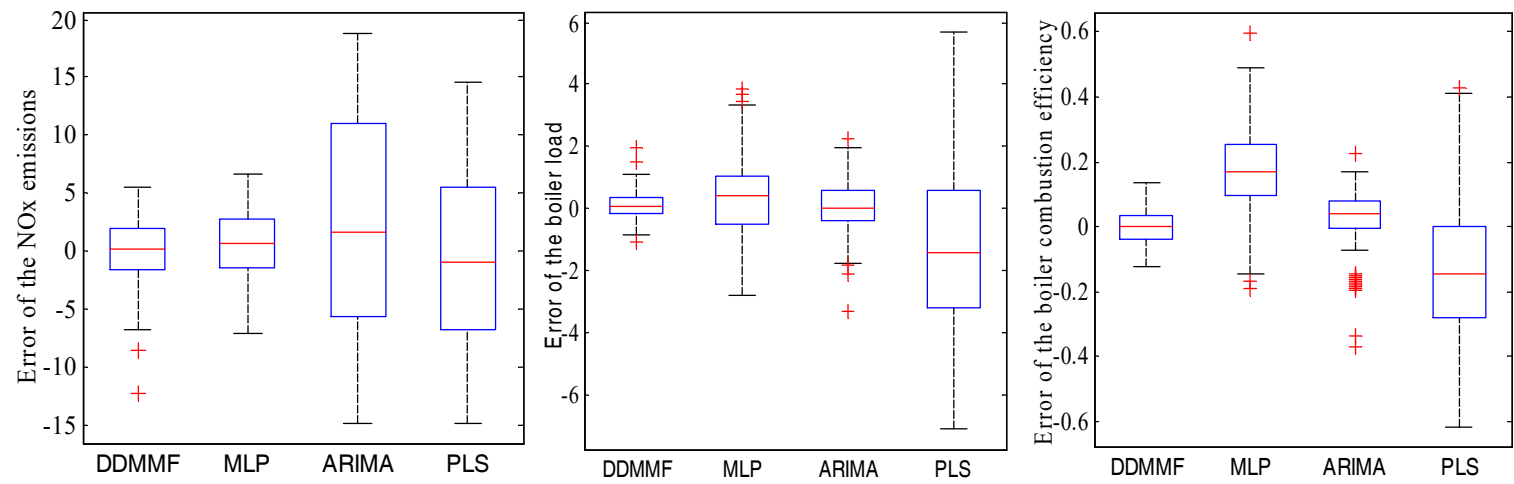

Figure 6. The prediction errors obtained from different prediction models for operating condition 2

Table 5. The prediction evaluation indicators of different objects for different models in operating condition 2.

\begin{tabular}{cccccccccc}
\hline & \multicolumn{3}{c}{ NOx Emissions } & \multicolumn{3}{c}{ Boiler Load } & \multicolumn{3}{c}{ Boiler Efficiency } \\
\hline Model & $\begin{array}{c}\text { MAE } \\
\left(\mathbf{m g} / \mathbf{m}^{3}\right)\end{array}$ & $\begin{array}{c}\text { RMSE } \\
\left(\mathbf{m g} / \mathbf{m}^{3}\right)\end{array}$ & $\begin{array}{c}\text { MARE } \\
(\mathbf{\%})\end{array}$ & $\begin{array}{c}\text { MAE } \\
(\mathbf{M W})\end{array}$ & $\begin{array}{c}\text { RMSE } \\
\mathbf{( M W )}\end{array}$ & $\begin{array}{c}\text { MARE } \\
\mathbf{( \% )}\end{array}$ & $\begin{array}{c}\text { MAE } \\
\mathbf{( \% )}\end{array}$ & $\begin{array}{c}\text { RMSE } \\
\mathbf{( \% )}\end{array}$ & MARE (\%) \\
\hline DDMMF & 1.518 & 1.674 & 0.329 & 0.519 & 1.789 & 0.003 & 0.021 & 0.474 & $1.5 \times 10^{-4}$ \\
MLP & 1.883 & 7.832 & 1.899 & 4.683 & 6.649 & 0.012 & 0.149 & 2.975 & $8.4 \times 10^{-4}$ \\
ARIMA & 5.405 & 15.062 & 1.054 & 0.001 & 6.634 & 0.005 & 0.128 & 0.981 & $3.7 \times 10^{-4}$ \\
PLS & 2.321 & 16.946 & 2.443 & 0.115 & 4.630 & 0.005 & 0.065 & 0.684 & $5.4 \times 10^{-4}$ \\
\hline
\end{tabular}

The prediction accuracy of the DDMMF model was better than the corresponding one obtained with the MLP, ARIMA and PLS models. For example, in case of operating condition 1 compared with the other predictive models, the MAE indicator of the DDMMF model for the NOx emissions prediction reduced by $0.391 \%, 33.685 \%$ and $26.885 \%$, respectively; the RMSE indicator was diminished by $4.753 \%, 52.331 \%$ and $15.009 \%$, respectively; and the MARE indicator decreased by $48.320 \%, 74.557 \%$ 
and $83.602 \%$, respectively. The runtime of the comparison models was $46.426 \mathrm{~s}, 52.678 \mathrm{~s}$ and $38.124 \mathrm{~s}$, respectively. And the runtime of the DDMMF model was only $27.844 \mathrm{~s}$. In this case, the MAE indicator of the DDMMF model for the boiler load prediction decreased by $88.928 \%, 73.028 \%$ and $67.557 \%$, respectively; the RMSE indicator reduced by $23.228 \%, 73.028 \%$ and $28.179 \%$, respectively; and the MARE indicator decreased by $51.754 \%, 61.357 \%$ and $19.373 \%$, respectively. The runtimes of the comparison models were $40.128 \mathrm{~s}, 43.324 \mathrm{~s}$ and $38.421 \mathrm{~s}$, respectively. The runtime of the DDMMF model was only $30.564 \mathrm{~s}$. Similarly, for the boiler combustion efficiency, the MAE of the DDMMF model reduced by $96.551 \%, 99.715 \%$ and $99.896 \%$, respectively; the RMSE diminished by $63.318 \%, 40.707 \%$ and $35.653 \%$, separately; and the MARE decreased by $62.630 \%, 94.816 \%$ and $93.517 \%$, respectively. The runtimes of the other models were $36.345 \mathrm{~s}, 32.157 \mathrm{~s}$ and $38.657 \mathrm{~s}$, respectively. The runtime of the DDMMF model was only $25.625 \mathrm{~s}$. Similar results were obtained for operating condition 2, the MAE indicator of DDMMF model for the NOx emissions prediction diminished by $19.343 \%, 71.906 \%$ and $44.512 \%$, respectively; the RMSE indicator reduced by $78.628 \%, 88.887 \%$ and $90.123 \%$, respectively; and the MARE indicator decreased by $82.696 \%, 68.832 \%$ and $86.545 \%$, respectively. The runtimes of other models were $36.175 \mathrm{~s}, 38.620 \mathrm{~s}$ and $32.265 \mathrm{~s}$, respectively. The runtime of the DDMMF model was only $28.658 \mathrm{~s}$. For the same operating condition and boiler load prediction, a $88.928 \%, 73.028 \%$ and $67.557 \%$ decrease in the MAE indicator of DDMMF model, a $23.228 \%, 73.028 \%$ and $28.179 \%$ decrease in the RMSE indicator and a $51.754 \%, 61.357 \%$ and $19.373 \%$ decrease in the MARE index was obtained, respectively. The runtimes of the comparison models were $34.659 \mathrm{~s}, 33.674 \mathrm{~s}$ and $35.658 \mathrm{~s}$, respectively. The runtime of the DDMMF model was only $29.467 \mathrm{~s}$. Finally, the boiler combustion efficiency prediction showed a $85.998 \%, 83.661 \%$ and $67.915 \%$ reduction in the MAE indicator of the DDMMF model, $84.067 \%, 51.682 \%$ and $30.702 \%$ decrements in the RMSE index and a $82.196 \%, 59.790 \%$ and $72.201 \%$ reduction in the MARE index, respectively. The runtimes of other models were $48.554 \mathrm{~s}, 52.214 \mathrm{~s}$ and $43.248 \mathrm{~s}$, respectively. The runtime of the DDMMF model was only $19.248 \mathrm{~s}$. The results of the present study indicate that the algorithm improved of the modeling accuracy and counting efficiency.

\section{Adaptive Nonlinear Model Predictive Control of the Boiler Combustion Efficiency}

The model predictive control (MPC) of the boiler combustion efficiency is described in this section. The overall control structure, including the prediction model, the rolling optimization, as well as the feedback correction is illustrated in Section 4.1. The rolling optimization and feedback correction are discussed in Sections 4.2 and 4.3, respectively. The validation of the designed model predictive controller is performed in Section 4.4.

\subsection{The Structure of the Proposed Model Predictive Controller}

The MPC algorithm consists of the prediction model, rolling optimization and feedback correction as shown in Figure 7. The LSSVM-based prediction model is optimized via the DE algorithm. Predictive models are provided for the NOx emissions, the boiler load, and the boiler combustion efficiency to predict the boiler combustion efficiency under the NOx emissions and the boiler load. Historical data and current production information are employed to predict the relevant object values at the current time. Then, the prediction information of the DDMMF is adopted to establish rolling optimization. The optimal controller parameters are obtained by solving this rolling optimization problem. This gives maximum boiler combustion efficiency under the NOx emissions and the boiler load constraints. Feedback correction is utilized to improve the proposed model accuracy. 


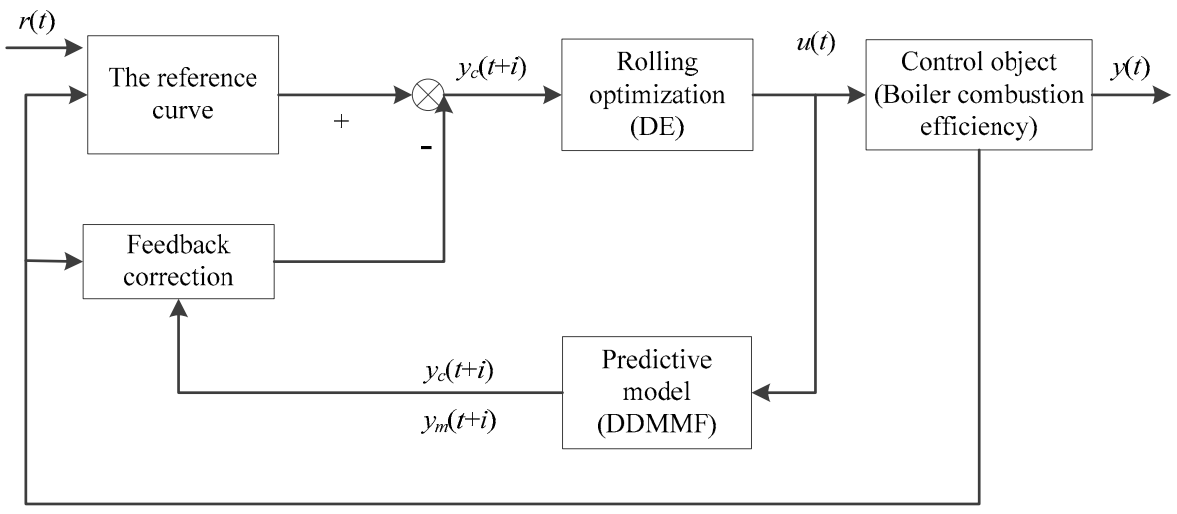

Figure 7. The proposed model predictive control structure.

\subsection{Rolling Optimization}

Rolling optimization is designed to obtain the optimal values of the controller parameters. The minimum control errors between the control output and expected value of boiler efficiency is taken as the control objective. The control constraints consist of three parts: (1) The error of NOx emission control output and expected output must be within 5\%; (2) the error of boiler load control output and expected output must be within 5\%; and (3) the control variables must satisfy the boundary constraints. The control output value of the NOx emissions and boiler load, and the optimal control variables are output when the control errors of the NOx emissions and boiler load meets the constraints and minimum requirements of the control objectives. The maximum boiler efficiency can be obtained by reasonably allocating control variables. The boiler load expected value is the actual operation value, the boiler is in a stable operation state when the boiler load control output can better follow the expected curve. As a result, the maximum boiler combustion efficiency is constructed by considering load constraints, pollutant emission constraints and boundary constraints could be obtained. An appropriate performance index is minimized to determine the control increment, such that $p$ future output values of boiler efficiency $Y_{B}$, track the desired value of the boiler combustion efficiency $\omega_{B}$. The boiler combustion efficiency is considered as the performance index of the MPC controller for achieving the rolling optimization. Thus, the following rolling optimization problem is defined:

$$
\begin{array}{ll}
\min & \left(\sum_{s=1}^{p}\left(Y_{B}-\omega_{B}^{s}\right)\right) \\
\text { s.t. } & Y_{B, h}=f\left(F c, M, A_{1}, A_{2}, A_{3}, A_{4}, P_{a}, S, O_{1}, O_{2}, T_{1}, T_{2}, T_{3}, T_{4}, P, \sigma, w_{B}, C, e_{i}, a_{i}, b, B^{*}\right) \\
& Y_{N_{x}, h}=f\left(F c, M, A_{1}, A_{2}, A_{3}, A_{4}, P_{a}, S, O_{1}, O_{2}, T_{1}, T_{2}, \sigma, w_{N_{x}}, C, e_{i}, a_{i}, b, N_{x}^{*}\right) \\
& Y_{L, h}=f\left(F c, M, A_{1}, A_{2}, A_{3}, A_{4}, P_{a}, S, \sigma, w_{L}, C, e_{i}, a_{i}, b, L^{*}\right) \\
& Y_{N x, h}^{M_{h}} \leq Y_{N_{x}, h} \leq Y_{N_{x}, h}^{U_{h}}, Y_{L, h}^{M_{h}} \leq Y_{L, h} \leq Y_{L, h}^{U_{h}}, u_{h}^{M_{h}} \leq u_{h} \leq u_{h}^{U_{h}}, s=1,2, \ldots, p, h=1,2
\end{array}
$$

where $\omega_{B}^{s}$ is the desired output value of the boiler efficiency under the sth minimization function. $p$ denotes the horizon of the minimization. $Y_{B, h}$ denotes the boiler combustion efficiency predicted value in the presence of the controlincrement for the $h$ th operating condition. $Y_{N x, h}^{M_{h}}$ is the allowed minimum value limit value of the NOx emissions under the $h$ th operating condition; $Y_{N x, h}^{U_{h}}$ is the upper limit value of the NOx emissions under the $h$ th operating condition. $Y_{L, h}^{M_{h}}$ is the lower bound of the load under the $h$ th operating condition; $Y_{L, h}^{U_{h}}$ is the upper bound of the load under the $h$ th operating condition. $u_{h}^{M_{h}}$ is the allowed minimum value limit value of the control variables under the $h$ th operating condition; $u_{h}^{U_{h}}$ is the upper bound of the control variables under the $h$ th operating condition; $u$ is the control variable.

To solve the rolling optimization problem and find the optimal controller parameters, a DE algorithm is utilized (its flowchart is given in Figure 8). According to Figure 8, the algorithm is given as follows. 
Step 1: The data is read. Then, the sampling time of the predictive model is determined to meet the rolling optimization requirements.

Step 2: The DE algorithm is initialized. The control variable is calculated as:

$$
u=u_{m}+\sum_{i=1}^{P} d_{i}\left(\omega_{B}-y(i)\right)
$$

Now, the particle denotes the $m$ th control variable, including $F c, M, A_{1}, A_{2}, A_{3}, A_{4}, P_{a}, S$.

Step 3: The $\mathrm{N}_{\mathrm{x}}$ and the $\mathrm{L}$ for any particle are calculated according to Equation (5).

Step 4: If the $\mathrm{N}_{\mathrm{x}}$ and the $\mathrm{L}$ requirements are satisfied, go to Step 5. Otherwise, set the relative particle fitness to 1000 and go to Step 6 .

Step 5: Compute the boiler combustion efficiency of each particle. Now, calculate the fitness through the following equation:

$$
\varepsilon(k)=\sqrt{\left(\sum_{k=1}^{p}\left|Y_{B}-\omega_{B}^{k}\right|^{2} /(p-1)\right)}
$$

where $Y_{B}$ denotes the predicted boiler combustion efficiency of the $k$ th predictive mode; $\omega_{B}^{k}$ is the desired boiler combustion efficiency at time $k$.

Step 6: Search the minimum fitness value.

Step 7: If the stopping condition is satisfied, stop the algorithm and show the optimal controller parameters, as well as the optimal fitness value. Otherwise, go to Step 8.

Step 8: If $g=G$, show the optimal controller parameters and the fitness value and stop the algorithm. Otherwise, go to Step 9.

Step 9: Update particles according to Equations (6)-(8). Set $g=g+p$ and return to Step 3.

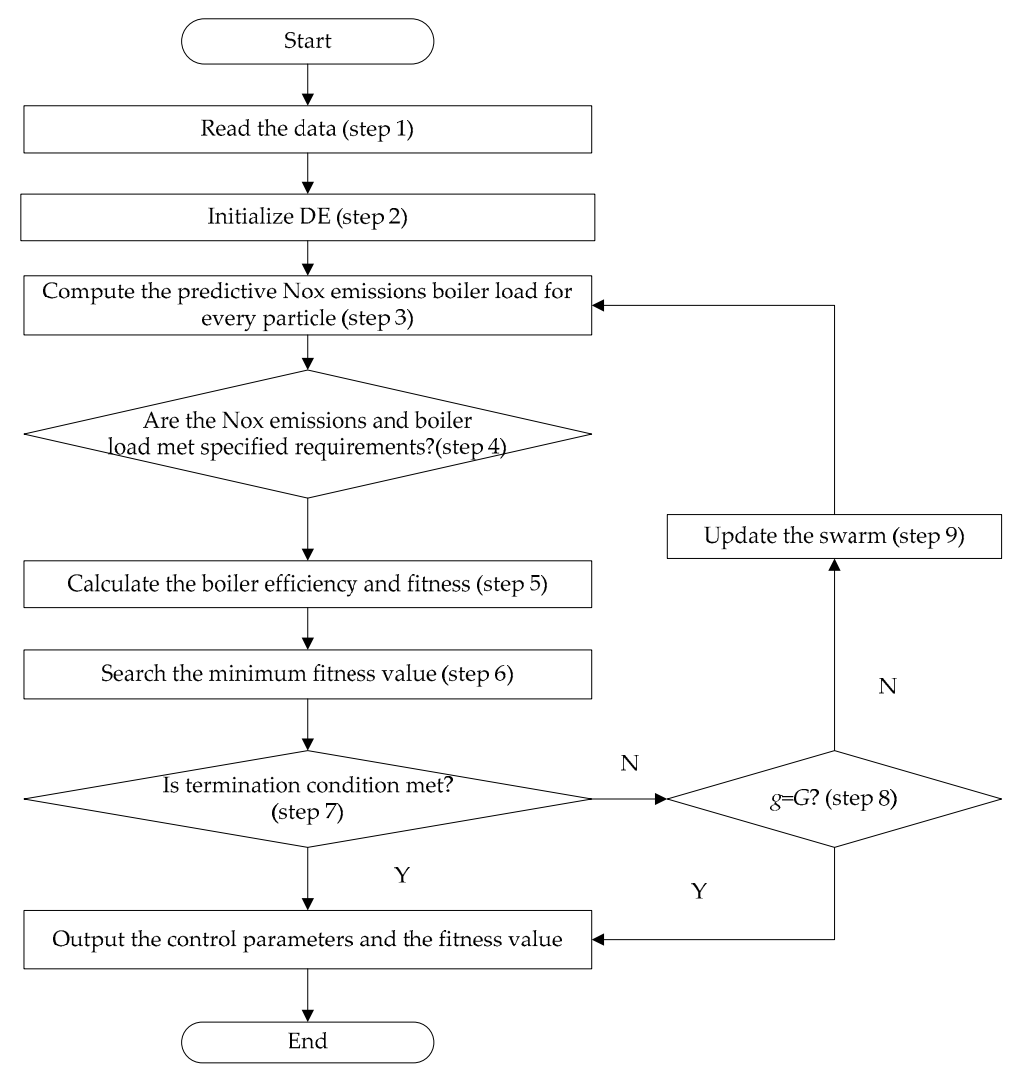

Figure 8. The rolling optimization flowchart. 


\subsection{Feedback Correction}

The NOx emissions and the boiler load are affected by serious factors, such as fuel combustion and operating condition. Then, the model correction strategy is employed to guarantee the predictive model accuracy. In other words, recent data is applied to reconstruct the predictive model when the prediction errors of the actual NOx emissions, the actual boiler load and the boiler combustion efficiency are larger than $5 \%$. The predictive model inaccuracy could be corrected through the model correction strategy. Therefore, the optimal results can be obtained via the model predictive control.

\subsection{Validation of the Model Predictive Control Results}

\subsubsection{Experiment Setup}

The model predictive control experimental data are shown in Table 6. The input variables of the predictive control model are obtained according to Equation (12) under two operating conditions.

Table 6. Dataset2.

\begin{tabular}{ccccccc}
\hline \multirow{2}{*}{ Parameter } & \multicolumn{3}{c}{ Number (Condition 1) } & \multicolumn{3}{c}{ Number (Condition 2) } \\
\cline { 2 - 7 } & $\boldsymbol{N}_{\boldsymbol{x}}$ & $\boldsymbol{B}$ & $\boldsymbol{L}$ & $\boldsymbol{N}_{\boldsymbol{x}}$ & $\boldsymbol{B}$ & $\boldsymbol{L}$ \\
\hline Test data (samples) & 300 & 300 & 300 & 270 & 270 & 270 \\
Sample Interval (min) & 1 & 1 & 1 & 1 & 1 & 1 \\
Input variable & 13 & 16 & 9 & 13 & 16 & 9 \\
Output variable & 1 & 1 & 1 & 1 & 1 & 1 \\
\hline
\end{tabular}

\subsubsection{Experimental Result Analysis}

In this study, the model predictive control strategy is employed to maximize boiler combustion efficiency under two operating conditions. To verify the proposed method performance, some experiments were performed using the real production data. The data sets under the two operating conditions are described in Table 7. The experimental results are given in Figures 9 and 10. The obtained results under the first and the second operating conditions are shown in Figures 9 and 10, respectively. Figure 9, Figure 10, and Table 7 demonstrate the superiority of the proposed model predictive controller (BMPC) to the proportion-integral-derivative (PID) controller. The as seen in Figures 9 and 10, with the model predictive control algorithm using in the boiler, it could be concluded that the NOx emissions control output values and boiler load control output values when the control variables were reasonably matched, which could follow the trajectory of a given curve better. In combination with Table 7, the boiler efficiency could be improved by adjusting the control values, when the NOx emissions control output errors and the boiler load control output errors were both within $\pm 5 \%$ under the two different operating conditions. The control output error was between the predicted value under the optimal variable and the expected value. The NOx emissions and boiler load were the predicted output values of the test data using the DDMMF method. The expected values of boiler efficiency were the actual values plus a $1.5 \%$ smoothing filter, the expected values of the NOx emissions were the actual values minus 10 , and the expected values of the boiler load were the actual output values. We can see from Table 7, the proposed approach compared with the PID controller could improve boiler efficiency by 1.613 percent and reduce NOx emissions by 1.887 percent for the first operating condition. In addition, it could improve boiler efficiency by 1.136 percent and reduce NOx emissions by 2.166 percent for the second condition, when the control variables satisfied the boundary constraints and the NOx emissions control output error and boiler load control output error were both within $\pm 5 \%$. Thus, based on the boiler key parameter model (NOx emissions, boiler load, boiler efficiency), the boiler combustion efficiency rolling optimization model was constructed by considering load constraints, pollutant emission constraints and boundary constraints, and the optimal 
controller parameters were calculated via an optimization model solved by the DE algorithm. Finally, the proposed BMPC provided effective tools for the operators.
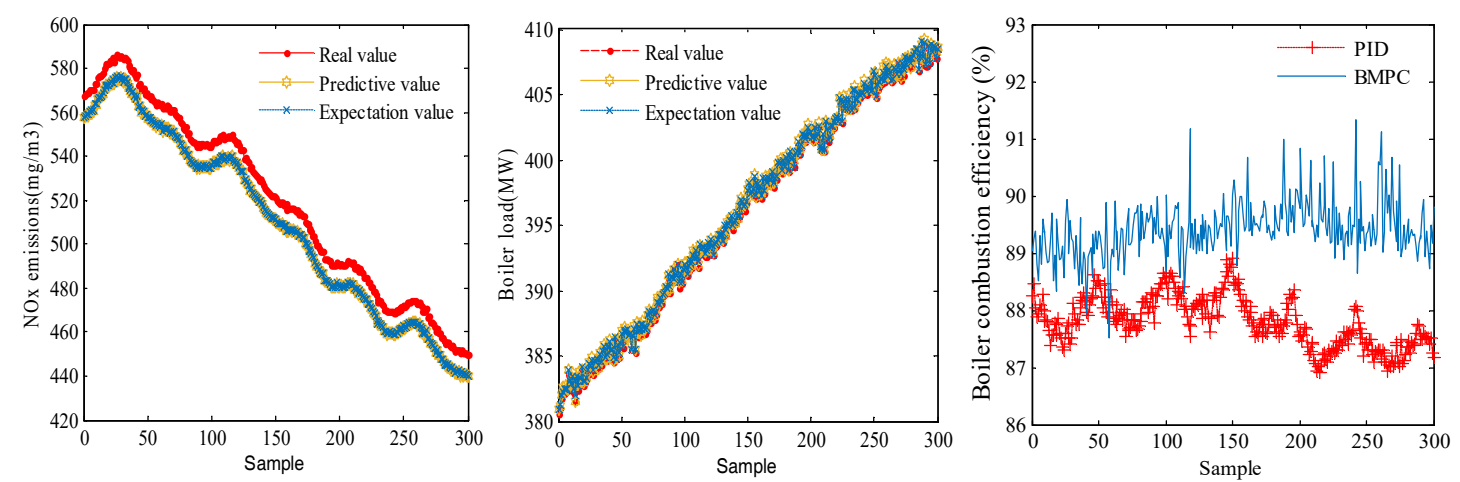

Figure 9. Theresults obtained with the model predictive control under operating condition 1.
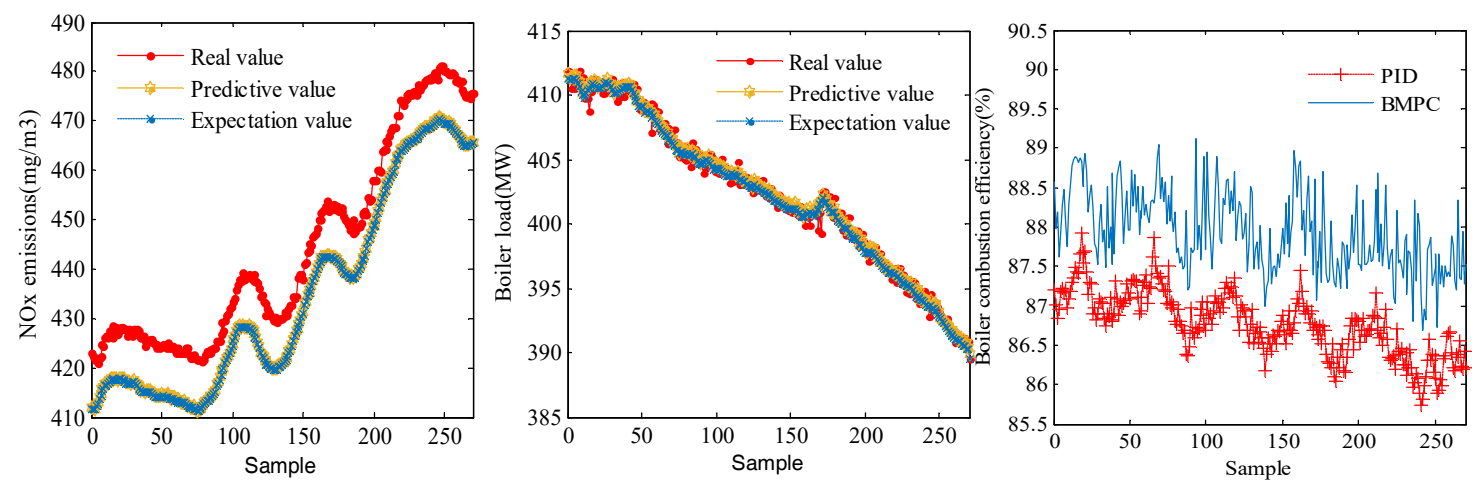

Figure 10. The results obtained with the model predictive control under operating condition 2.

Table 7. Data description.

\begin{tabular}{ccccc}
\hline Description & $\begin{array}{c}\text { The Predictive } \\
\text { Control Error of } \\
\text { NOx Emissions / } \\
\text { Boiler Load (\%) }\end{array}$ & $\begin{array}{c}\text { The Percentage of } \\
\text { NOx Emissions } \\
\text { Decline by BMPC }\end{array}$ & $\begin{array}{c}\text { The Percentage of } \\
\text { Boiler Efficiency } \\
\text { Improvement by BMPC }\end{array}$ & $\begin{array}{c}\text { Number of } \\
\text { Samples }\end{array}$ \\
\hline $\begin{array}{c}\text { the operation } \\
\text { condition 1 } \\
\text { the operation } \\
\text { condition 2 }\end{array}$ & $-4.911 \sim 4.969$ & 1.887 & 1.613 & 300 \\
\hline
\end{tabular}

\section{Conclusions}

In this paper, a nonlinear model predictive control approach for different operating conditions was proposed to maximize the boiler combustion efficiency in the presence of the NOx emissions and the boiler load variations. This approach had five distinctive features: (1) PCA was employed to generate the required input for the prediction model and reduce the input dimension; (2) the KNN classifier was utilized to deal with various working conditions; (3) the LSSVM parameters were dynamically optimized by the DE algorithm, and additionally, the model output value was compensated to improve the prediction accuracy; (4) the optimal values of the control variables were obtained using the proposed adaptive nonlinear predictive control approach; (5) considering the boiler combustion efficiency, the NOx emissions, and the boiler load, the DE algorithm was employed to solve the rolling optimization problem. Experimental verification based on the practical data was carried out to verify the performance of the proposed method. According to the obtained results, both the modeling and controlling were effective. The DDMMF model could accurately predict the 
different objects under different operation conditions. The BMPC control strategy, based on DDMMF model, was proposed to improve the quality of production and reduce energy consumption, and to lay the foundation for a power enterprise to bring high efficiency and low emission. This provides an appropriate method that could be employed in production applications.

Future research will be dedicated to selecting the appropriate kernel function of the LSSVM under different conditions to meet the modeling requirement and improve the predictive performance of the DDMMF.

Author Contributions: Z.T. designed the research and the article structure, and revised the manuscript. X.W. carried out the experiments. S.C. revised the manuscript. All authors read and approved the final paper.

Funding: The authors would express their appreciation to the National Natural Science Foundation of China (NO.61503072 and NO.51606035) and the Science and Technology Development Plan of Jilin Province (NO. 20190201095JC, 20190201098JC).

Conflicts of Interest: The authors declare no conflict of interest.

\section{Acronyms}

\begin{tabular}{|c|c|c|c|}
\hline NOx & Nitrogen Oxides & CFD & Computational fluid dynamics \\
\hline ARIMA & Autoregressive integrated moving average & PLS & Partial least squares \\
\hline ANN & Artificial neural networking & $\mathrm{BP}$ & Back-propagation \\
\hline MLP & Multilayer perceptron & LSSVM & Least square support vector machine; \\
\hline $\mathrm{DE}$ & Differential evolution & SIS & Supervisor information system \\
\hline DCS & Distribution control system & PCA & Principal component analysis \\
\hline KNN & Kth Nearest Neighbor & PSO & Particle swarm optimization \\
\hline GA & Genetic algorithm & ADRC & Active disturbance rejection controller \\
\hline MFC-VRFT & $\begin{array}{l}\text { Model-Free control and virtual reference } \\
\text { feedback tuning }\end{array}$ & MPC & Model predictive control \\
\hline B & Boiler efficiency & $\mathrm{L}$ & Boiler load \\
\hline $\mathrm{N}_{\mathrm{x}}$ & NOx emissions & DELSSVM & DE-based LSSVM \\
\hline MAE & Mean absolute error & MAE & Mean absolute error \\
\hline RMSE & Root mean square error & MAPE & Mean absolute percentage error \\
\hline DDMMF & $\begin{array}{l}\text { A data-driven modeling method with feature } \\
\text { selection capability }\end{array}$ & BMPC & Model predictive controller \\
\hline PID & Proportion-integral-derivative & RBF & Radial based function \\
\hline
\end{tabular}

\section{References}

1. Ławryńczuk, M. Nonlinear predictive control of a boiler-turbine unit: A state-space approach with successive on-line model linearisation and quadratic optimisation. ISA Trans. 2017, 67, 475-495. [CrossRef] [PubMed]

2. Zhou, H.; Zheng, L.; Cen, K. Computational intelligence approach for NOx emissions minimizationin a coal-fired utility boiler. Energy Convers. Manag. 2010, 51, 580-586. [CrossRef]

3. Li, K.; Thompson, S.; Peng, J.X. Modeling and prediction of NOx emission in a coal-fired power generation plant. Control Eng. Pract. 2004, 12, 707-723. [CrossRef]

4. Gao, Y.; Zeng, D.; Liu, J.; Jian, Y. Optimization control of a pulverizing system on the basis of the estimation of the outlet coal powder flow of a coal mill. Control Eng. Pract. 2017, 63, 69-80. [CrossRef]

5. Ma, J.; Xu, F.; Huang, K.; Huang, R. Improvement on the linear and nonlinear auto-regressive model for predicting the NOx emission of diesel engine. Neurocomputing 2016, 207, 150-164. [CrossRef]

6. Fan, H.; Zhang, Y.; Su, Z.; Wang, B. A dynamic mathematical model of an ultra-supercritical coal fired once-through boiler-turbine unit. Appl. Energy 2017, 189, 654-666. [CrossRef]

7. Kim, B.S.; Kim, T.Y.; Park, T.C.; Yeo, Y.K. Comparative study of estimation methods of NOx emission with selection of input parameters for a coal-fired boiler. Korean J. Chem. Eng. 2018, 35, 1779-1790. [CrossRef]

8. Strušnik, D.; Golob, M.; Avsec, J. Artificial neural networking model for the prediction of high efficiency boiler steam generation and distribution. Simul. Model. Pract. Theory 2015, 57, 58-70. [CrossRef] 
9. Yin, L.B.; Liu, G.C.; Zhou, J.L.; Liao, Y.F.; Ma, X.Q. A calculation method for CO2 emission in utility boilers based on BP neural network and carbon balance. Energy Procedia 2017, 105, 3173-3178. [CrossRef]

10. Liukkonen, M.; Hälikkä, E.; Hiltunen, T.; Hiltunen, Y. Dynamic soft sensors for NOx emissions in a circulating fluidized bed boiler. Appl. Energy 2012, 97, 483-490. [CrossRef]

11. Lv, Y.; Liu, J.; Yang, T.; Zeng, D. A novel least squares support vector machine ensemble model for NOx emission prediction of a coal-fired boiler. Energy 2013, 55, 319-329. [CrossRef]

12. Lv, Y.; Yang, T.; Liu, J. An adaptive least squares support vector machine model with a novel update for NOx emission prediction. Chemom. Intell. Lab. Syst. 2015, 145, 103-113. [CrossRef]

13. Xu, C.; Gao, S.; Li, M. A novel PCA-based microstructure descriptor for heterogeneous material design. Comput. Mater. Sci. 2017, 130, 39-49. [CrossRef]

14. He, F.; Zhang, L. Prediction model of end-point phosphorus content in BOF steelmaking process based on PCA and BP neural network. J. Process Control 2018, 66, 51-58. [CrossRef]

15. Sayed, M.; Gharghory, S.M.; Kamal, H.A. Gain tuning PI controllers for boiler turbine unit using a new hybrid jump PSO. J. Electr. Syst. Inf. Technol. 2015, 2, 99-110. [CrossRef]

16. Anarghya, A.; Rao, N.; Nayak, N.; Tirpude, A.R.; Harshith, D.N.; Samarth, B.R. Optimized ANN-GA and experimental analysis of the performance and combustion characteristics of HCCI engine. Appl. Eng. 2018, 132, 841-868. [CrossRef]

17. Han, J.; Wang, H.F.; Jiao, G.T.; Cui, L.M.; Wang, Y.R. Research on active disturbance rejection control technology of electromechanical actuators. Electronics 2018, 7, 174. [CrossRef]

18. Roman, R.C.; Radac, M.B.; Precup, R.E.; Pertriu, E.M. Virtual reference feedback tuning of model-Free control algorithms for servo systems. Machinces 2018, 5, 25. [CrossRef]

19. Pan, Q.K.; Suganthan, P.N.; Wang, L.; Gao, L.; Mallipeddi, R. A differential evolution algorithm with self-adapting strategy and control parameters. Comput. Oper. Res. 2011, 38, 394-408. [CrossRef]

20. Yu, X.; Yu, X.; Lu, Y.; Yen, G.G.; Cai, M. Differential evolution mutation operators for constrained multi-objective optimization. Appl. Soft Comput. 2018, 67, 452-466. [CrossRef]

21. Afram, A.; Janabi-Sharifi, F. Supervisory model predictive controller (MPC) for residential HVAC systems: Implementation and experimentation on archetype sustainable house in Toronto. Energy Build. 2017, 154, 268-282. [CrossRef]

22. Balram, P.; Tuan, L.A.; Carlson, O. Comparative study of MPC based coordinated voltage control in LV distribution systems with photovoltaics and battery storage. Electr. Power Energy Syst. 2018, 95, 227-238. [CrossRef]

(C) 2019 by the authors. Licensee MDPI, Basel, Switzerland. This article is an open access article distributed under the terms and conditions of the Creative Commons Attribution (CC BY) license (http://creativecommons.org/licenses/by/4.0/). 